\title{
PERANCANGAN SISTEM INFORMASI PARIWISATA PULAU LOMBOK DENGAN MENGGUNAKAN METODE SIMPLE ADDITIVE WEIGHTING
}

\author{
Lalu Delsi Samsumar ${ }^{1}$, Novianti Puspitasari² \\ STMIK Mataram ${ }^{1}$ \\ Universitas Mulawarman² \\ lalu.ellsyam@gmail.com
}

\begin{abstract}
Abstrak - Sistem Informasi Pariwisata ini dirancang dengan menggunakan pendekatan metode Simple Additive Weighting Method (SAW) dalam menentukan objek wisata yang paling baik untuk dikunjungi. Sistem informasi pariwisata ini menyediakan informasi mengenai pariwisata yang ada di Pulau Lombok dan membantu pengguna menentukan objek wisata yang paling baik untuk dikunjungi berdasarkan tingkat kepentingan masing - masing kriteria yang disediakan. Proses penentuan dilakukan dengan cara memilih kategori wisata yang diinginkan pada form yang telah disediakan kemudian memberikan tingkat kepentingan pada setiap kriteria yang ditawarkan. Selain itu Sistem Informasi Pariwisata ini juga dapat menjadi sarana promosi usaha bagi masyarakat dan UKM yang memiliki usaha di bidang pariwisata. Tujuan penelitian ini adalah untuk merancang sistem informasi pariwisata berbasis web agar memudahkan para wisatawan dan masyarakat dalam mendapatkan informasi mengenai pariwisata di Pulau Lombok. Metode yang digunakan adalah dengan melakukan observasi dan studi literatur, sedangkan untuk perancangan sistem meliputi analisis kebutuhan perangkat lunak, dan perancangan perangkat lunak. Diharapkan dengan adanya Sistem Informasi Pariwisata ini dapat dikembangkan dan digunakan untuk membantu masyarakat dalam mendapatkan informasi mengenai pariwisata yang ada di Pulau Lombok serta mendokumentasikan informasi mengenai pariwisata dan infrastruktur pendukungnya.
\end{abstract}

Kata Kunci: Sistem Informasi Pariwisata, Pariwisata Pulau Lombok, Simple Additive Weighting Method

\section{Latar Belakang}

Sistem yang berbasis informasi pada dasarnya adalah salah satu bentuk implementasi dari kebutuhan terhadap suatu informasi yang mengharuskan sistem menangani kebutuhan informasi tersebut secara cepat, akurat dan dinamis. Salah satu cara untuk mensosialisasikan dan mengaplikasikan kebutuhan tersebut adalah dengan menggunakan sistem informasi berbasis web, artinya sistem informasi tersebut dapat menangani suatu kebutuhan informasi secara global.

Pulau Lombok merupakan salah satu pulau yang terletak di provinsi Nusa Tenggara Barat di mana Pulau Lombok memiliki alam dan panorama yang indah yang beraneka raga. Banyaknya objek wisata yang terdapat di Pulau Lombok membuat wisatawan mengalami kesulitan untuk menentukan tujuan wisata.

Metode Simple Additive Weighting (SAW) dapat digunakan untuk membantu wisatawan dalam menentukan tujuan wisata. Metode SAW dapat menentukan nilai bobot untuk setiap atribut, kemudian dilanjutkan dengan perangkingan yang akan menyeleksi alternatif terbaik dari sejumlah alternatif yang tersedia, dalam hal ini alternatif yang dimaksud adalah objek wisata yang terbaik untuk dikunjungi berdasarkan kriteria-kriteria yang ditentukan oleh wisatawan.

Tujuan penelitian ini adalah untuk merancang sistem informasi pariwisata berbasis web agar memudahkan para wisatawan dan masyarakat dalam mendapatkan informasi mengenai pariwisata di Pulau Lombok.

Diharapkan dengan adanya Sistem Informasi Pariwisata ini dapat dikembangkan dan digunakan untuk membantu masyarakat dalam mendapatkan informasi mengenai pariwisata yang ada di Pulau Lombok serta mendokumentasikan informasi mengenai pariwisata dan infrastruktur pendukungnya.

\section{Kajian Pustaka}

\section{a. Sistem Informasi}

Sistem informasi merupakan sekumpulan elemen yang berhubungan satu sama lain untuk membentuk satu kesatuan yang menggabungkan data, memproses, menyimpan dan mendistribusikannya, sehingga dapat digunakan sebagai bahan dalam pengambilan keputusan dan mengendalikannya. Sistem informasi juga 
memiliki arti sebuah sistem buatan manusia yang secara umum terdiri atas sekumpulan komponen berbasis komputer yang dibuat untuk menghimpun, menyimpan, dan mengelola data serta menyediakan informasi keluaran kepada pemakai. Pengertian sistem informasi adalah suatu kombinasi dari orang-orang, fasilitas teknologi, media, prosedur-prosedur, dan pengendalian ditujukan untuk mendapat jalur komunikasi penting, memproses tipe transaksi rutin tertentu, member sinyal kepada manajemen dan yang lainnya terhadap kejadian-kejadian internal dan eksternal yang penting dan menyediakan suatu dasar untuk pengambilan keputusan yang cerdik [1], [2].

\section{b. Simple Additive Weighting Method (SAW)}

Metode SAW sering juga dikenal istilah metode penjumlahan terbobot. Konsep dasar metode SAW adalah mencari penjumlahan terbobot dari rating kinerja pada setiap alternatif pada semua atribut. Metode SAW membutuhkan proses normalisasi matriks keputusan (X) ke suatu skala yang dapat diperbandingkan dengan semua rating alternatif yang ada.

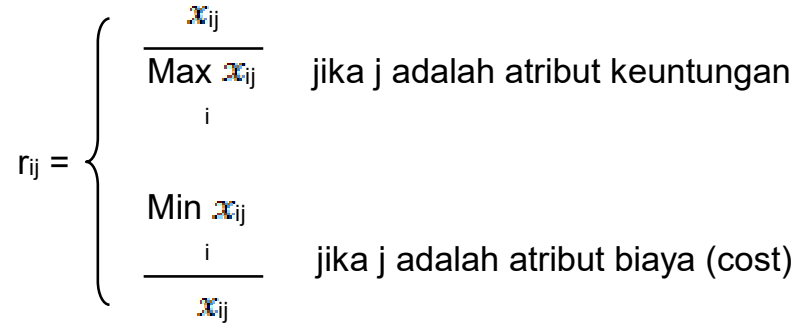

dimana $r_{i j}$ adalah rating kinerja ternormalisasi dari alternatif $A_{i}$ pada atribut $C_{j} ; i=1,2, \ldots, m$ dan $\mathrm{j}=1,2, \ldots, \mathrm{n}$. Nilai preferensi untuk setiap alternatif $\left(\mathrm{V}_{\mathrm{i}}\right)$ diberikan sebagai:

$$
\mathrm{V}_{\mathrm{i}}=\sum_{j=1}^{n} \quad \mathrm{w}_{\mathrm{j}} \mathrm{r}_{\mathrm{ij}}
$$

Nilai $V_{i}$ yang lebih besar mengindikasikan bahwa alteratif $A_{i}$ lebih terpilih [3], [4], [5].

\section{Metode}

Metode yang digunakan dalam perancangan sistem meliputi observasi, studi literatur, analisis kebutuhan pernagkat lunak, dan perancangan perangkat lunak .

\section{Perancangan Sistem dan Hasil}

\section{a. Rancangan Model yang Diusulkan}

Berdasarkan hasil observasi, maka diperlukan sebuah media berupa sebuah sistem informasi pariwisata untuk mempermudah wisatawan dalam mendapatkan informasi mengenai objek wisata yang dapat diakses kapan dan di mana saja. Berikut adalah model proses bisnis yang diusulkan seperti pada gambar 1 di bawah ini.

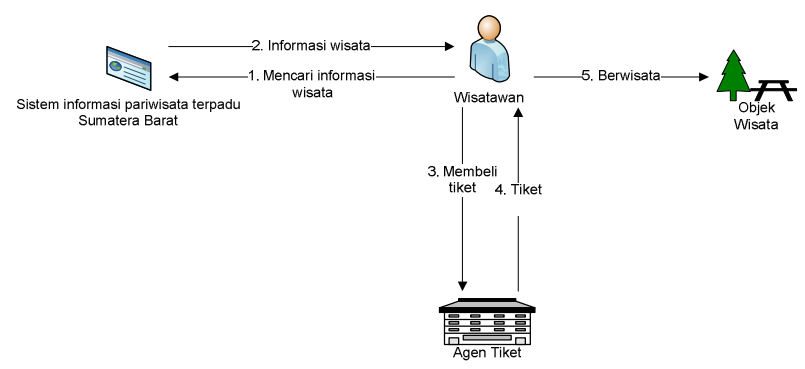

Gambar 1 Rancangan Model Proses Bisnis

Dari gambar 1 di atas dapat dijelaskan secara deskriptif mengenai alur proses yang akan dijalankan. Pertama wisatawan mencari informasi mengenai objek wisata melalui sistem informasi pariwisata, setelah mendapatkan informasi mengenai objek wisata, wisatawan membeli tiket perjalanan menuju daerah wisata yang dituju, selanjutnya wisatawan berangkat menuju daerah tujuan wisata.

\section{b. Model Keputusan}

Model yang diusulkan pada sistem informasi pariwisata ini menggunakan basis pengetahuan dengan menggunakan metode simple additive weighting atau penjumlahan terbobot. Penyusunan basis pengetahuan tersebut berupa data alternatif yang digunakan untuk perhitungan dalam membuat keputusan. Keputusan diambil berdasarkan tingkat kepentingan yang dimasukkan oleh pengguna untuk setiap kriteria pada kategori wisata yang dipilih. Adapun kriteria yang ditawarkan untuk masing-masing kategori wisata terdiri dari Kategori Wisata Alam dan Pegunungan, Kategori Wisata Pantai, Kategori Wisata Budaya dan Sejarah, Kategori Wisata Air. Masing-masing kategori memiliki kriteria yang sama dalam menentukan perhitungan untuk model keputusan seperti pada tabel 1 di bawah ini. 
Tabel 1 Kriteria Wisata

\begin{tabular}{ccc}
\hline $\begin{array}{c}\text { Kode } \\
\text { Bobot }\end{array}$ & Kriteria & Jenis / Satuan \\
\hline C1 & Harga tiket masuk & Kuantitas / Rupiah \\
\hline C2 & Jumlah pemandu & Kuantitas \\
\hline C3 & Transportasi & Kualitas \\
\hline C4 & Jumlah penginapan & Kuantitas \\
\hline C5 & $\begin{array}{c}\text { Jarak dari wisata } \\
\text { terdekat }\end{array}$ & $\begin{array}{c}\text { Kuantitas/ } \\
\text { Kilometer }\end{array}$ \\
\hline
\end{tabular}

Untuk menentukan objek wisata yang layak dikunjungi pada kategori wisata tertentu, maka user dapat memberikan tingkat kepentingan untuk masing-masing kriteria yang ditawarkan pada kategori wisata tersebut. Tingkat kepentingan untuk setiap kriteria dinilai dengan 1 sampai 5 , yaitu : Sangat Rendah $=1$, Rendah $=2$, Cukup $=$ 3 , Tinggi $=4$, dan Sangat Tinggi $=5$.

\section{c. Perhitungan Simple Additive Weighting Method}

Pada perhitungan data mengunakan Simple Additive Weighting Method ini semua nilai bobot diberikan pada setiap alternatif objek wisata di setiap kriterianya, seperti terlihat pada tabel 2 berikut.

\section{Tabel 2 Nilai Bobot Kriteria}

Misalkan user ingin menentukan objek wisata yang layak dikunjungi untuk kategori objek wisata budaya dan sejarah dengan kriteria yang ditawarkan berupa C1 = harga tiket masuk, C2 = Nilai Historis, C3 = Transportasi, C4 = Jumlah Penginapan, dan C5 = Jarak dari wisata terdekat. Berikut adalah nilai bobot dari setiap lokasi wisata seperti terlihat pada tabel 1 berikut ini.

Selanjutnya matriks keputusan yang dibentuk dari tabel nilai bobot sebagai berikut :

$$
X=\mid \begin{array}{rrrrr}
15000 & 3 & 3 & 2 & 2 \\
5000 & 3 & 2 & 2 & 4 \\
10000 & 2 & 4 & 3 & 5 \\
2000 & 3 & 6 & 2 & 9 \\
6000 & 2 & 7 & 3 & 3
\end{array}
$$

Selanjutnya dilakukan normalisasi nilai matriks $\mathrm{X}$, sebagai berikut:

Untuk C1 adalah kriteria harga, maka dikategorikan sebagai nilai minimum, dengan kata lain semakin rendah semakin bagus (cost).

$$
\begin{aligned}
& \mathrm{r} 11=\frac{\min (15000,5000,10000,2000,6000)}{15000}=\frac{2000}{15000}=0.13 \\
& \mathrm{r} 21=\frac{\min (15000,5000,10000,2000,6000)}{5000}=\frac{2000}{5000}=0.4 \\
& \mathrm{r} 31=\frac{\min (15000,5000,10000,2000,6000)}{10000}=\frac{2000}{10000}=0.2 \\
& \mathrm{r} 41=\frac{\min (15000,5000,10000,2000,6000)}{2000}=\frac{2000}{2000}=1 \\
& \mathrm{r} 51=\frac{\min (15000,5000,10000,2000,6000)}{6000}=\frac{2000}{6000}=0.33
\end{aligned}
$$

Untuk C5 adalah kriteria jarak, maka juga dikategorikan sebagai nilai minimum (cost) sehingga perhitungan normalisasi matriknya sama dengan C1. Untuk C2 adalah kriteria nilai historis, maka dikategorikan sebagai nilai maksimum, dengan kata lain semakin tinggi semakin bagus (benefit).

$$
\mathrm{r} 12=\frac{3}{\max (3,3,2,1,2)}=\frac{3}{3}=1
$$

\begin{tabular}{cccccc}
\hline \multirow{2}{*}{$\begin{array}{c}\text { Alternatif } \\
\text { Wisata }\end{array}$} & \multicolumn{5}{c}{ Kriteria } \\
\cline { 2 - 6 } W1 & C2 & C3 & C4 & C5 \\
\hline Wisata 1 & 15000 & 3 & 3 & 2 & 2 \\
\hline Wisata 2 & 5000 & 3 & 2 & 2 & 4 \\
\hline Wisata 3 & 10000 & 2 & 6 & 3 & 5 \\
\hline Wisata 4 & 2000 & 3 & 4 & 2 & 9 \\
\hline Wisata 5 & 6000 & 2 & 7 & 3 & 3 \\
\hline r22 $=\frac{2}{\max (3,3,2,1,2)}=\frac{2}{3}=0.67$ \\
r32 $=\frac{3}{\max (3,3,2,1,2)}=\frac{1}{3}=1$ \\
$\mathrm{r} 42=\frac{2}{\max (3,3,2,1,2)}=\frac{2}{3}=0.67$
\end{tabular}

Untuk C3 dan C4 juga dikategorikan sebagai nilai maksimum (benefit) sehingga perhitungan 
normalisasi matriknya sama dengan $\mathrm{C} 2$. Sehingga diperoleh matrik ternormalisasi $\mathrm{R}$ sebagai berikut:

$\mathrm{R}=\left|\begin{array}{ccccc}0.13 & 1 & 0.43 & 0.67 & 1 \\ 0.4 & 1 & 0.29 & 0.67 & 0.5 \\ 0.2 & 0.67 & 0.86 & 1 & 0.4 \\ 1 & 1 & 0.57 & 0.67 & 0.22 \\ 0.33 & 0.67 & 1 & 1 & 0.67\end{array}\right|$

Kemudian user memberikan nilai kepentingannya pada masing-masing kriteria sebagai berikut:

$$
W=\{3,5,4,1,5\}
$$

Selanjutnya dilakukanlah proses perangkingan untuk mendapatkan hasil alternatif wisata terbaik sebagai berikut:

$$
\begin{aligned}
\text { V1 } & =(3)(0,13)+(5)(1)+(4)(0,43)+(1)(0.67)+(5)(1) \\
& =12,78 \\
\text { V2 } & =(3)(0,4)+(5)(1)+(4)(0,29)+(1)(0.67)+(5)(0,5) \\
& =10,51 \\
\text { V3 } & =(3)(0,2)+(5)(0,67)+(4)(0,86)+(1)(1)+(5)(0,4) \\
& =10,36 \\
\text { V4 } & =(3)(1)+(5)(1)+(4)(0,57)+(1)(0.67)+(5)(0,22) \\
& =12,06 \\
\text { V5 } & =(3)(0,33)+(5)(0,67)+(4)(1)+(1)(1)+(5)(0,67) \\
& =12,67
\end{aligned}
$$

Nilai terbesar ada pada $\mathrm{V} 1$ sehingga alternatif objek wisata 1 adalah alternatif yang terpilih sebagai objek wisata yang layak dikunjungi.

\section{d. Perancangan UML}

\section{1) Use Case Diagram}

Sisitem Informasi Pariwisata ini memiliki tiga pengguna yakni admin, anggota, dan pengguna biasa. Admin bertugas mengelola data, informasi, dan content. Anggota (member) adalah pengguna yang telah terdaftar, dan pengguna biasa adalah pengguna yang belum terdaftar. Setiap anggota memiliki hak akses dan aktivitas yang bereda antara satu dengan yang lainnya di dalam sistem, seperti yang terlihat pada gambar 2 berikut ini. 


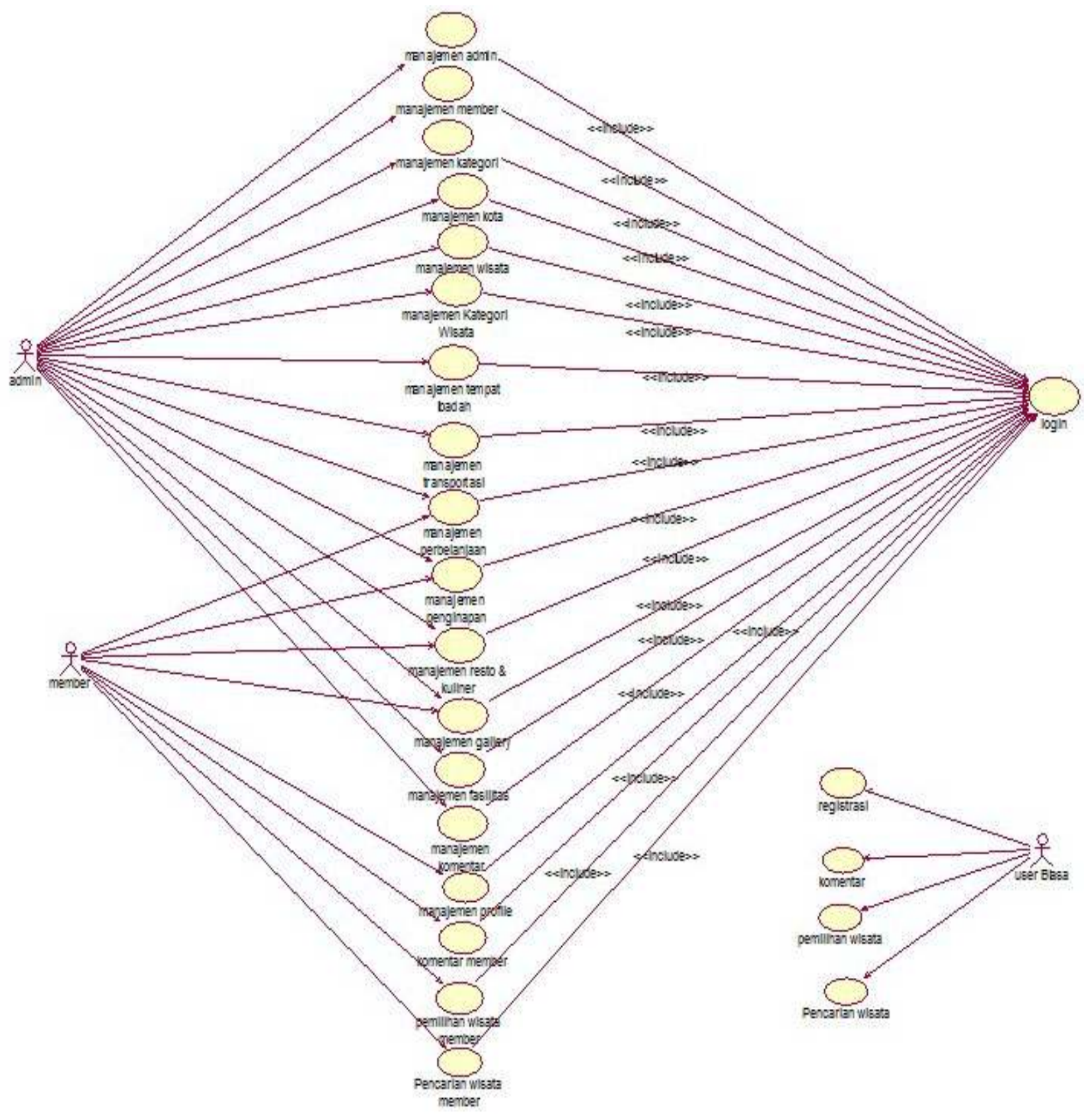

Gambar 2 Use Case Diagram 


\section{2) Activity Diagram}

Activity diagram menggambarkan berbagai aliran aktifitas dalam aplikasi yang dirancang, bagaimana aliran aktifitas dalam sistem tersebut berawal, decision (keputusan) yang mungkin terjadi dan bagaimana aktifitas tersebut berakhir. Terdapat beberapa activity diagram yang dihasilkan dalam sistem yang dibuat, yaitu :

\section{a. Activity Diagram Manajemen Admin}

Untuk melakukan manajemen admin, admin harus melakukan login terlebih dahulu. Ketika telah login dan valid maka selanjutnya dapat melakukan manajemen admin yaitu ubah data admin. Untuk detail proses seperti terlihat pada gambar 3 berikut.

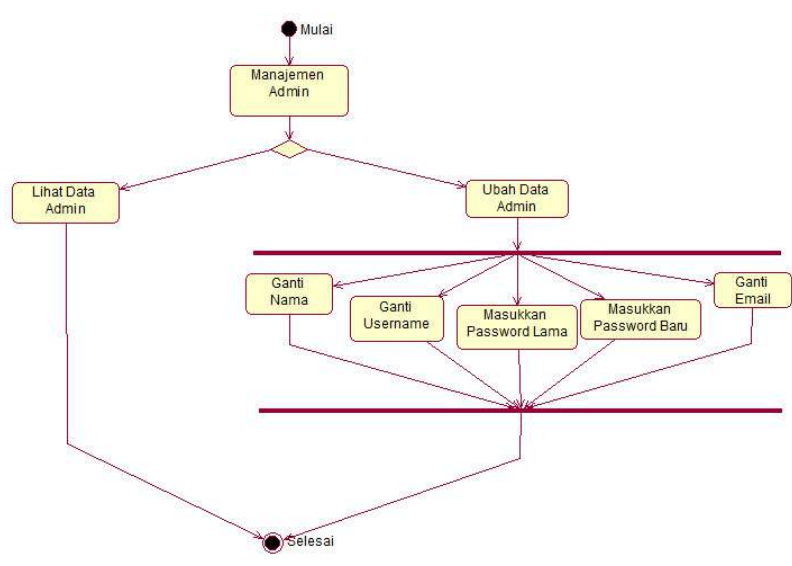

Gambar 3 Activity Diagram Manajemen Admin

\section{b. Activity Diagram Manajemen Anggota (Member)}

Untuk melakukan manajemen anggota, admin harus melakukan login terlebih dahulu. Ketika telah login dan valid maka selanjutnya dapat melakukan manajemen anggota yaitu mengubah dan menghapus data anggota. Untuk detail proses seperti terlihat pada gambar 4 berikut.

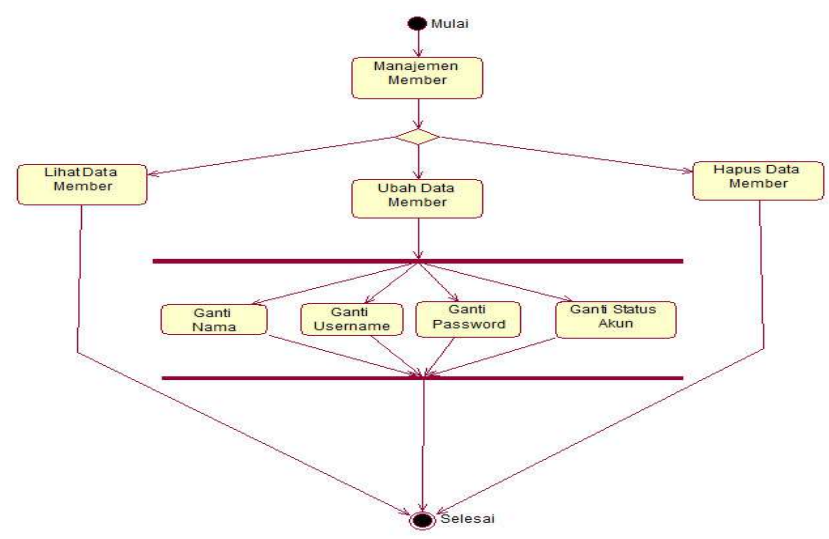

Gambar 4 Activity Diagram Manajemen Member

\section{c. Activity Diagram Manajemen Kategori}

Untuk melakukan manajemen kategori, admin harus melakukan login terlebih dahulu. Ketika telah login dan valid maka selanjutnya dapat melakukan manajemen kategori yaitu tambah, ubah dan hapus data kategori. Untuk detail proses seperti terlihat pada gambar 5 .

Gambar 5 Activity Diagram Manajemen Kategori



e. Perancangan Basis Data

Dalam merancang basis data perlu dibuat tabeltabel dan menentukan relasi antar tabel pada database yang akan digunakan dalam sistem. Adapun struktur tabel tersebut terdiri dari 23 tabel meliputi Tabel Admin, Tabel Activity, Tabel Alternatif, Tabel Bobot, Tabel Galery, Tabel Infrastruktur, Tabel KatInfrastruktur, Tabel Katshop, Tabel Katibadah, Tabel Kattrans, Tabel Katwisata, Tabel Kepentingan, Tabel Komentar, Tabel Kota, Tabel Member, Tabel Objekwisata, Tabel Penginapan, Tabel Perbelanjaan, Tabel Rating, Tabel Resto, Tabel Statistik, Tabel Tempat Ibadah, dan Tabel Transportasi. Rancangan relasi antar tabel untuk sistem informasi pariwisata ini diilustrasikan seperti gambar 6 berikut. 


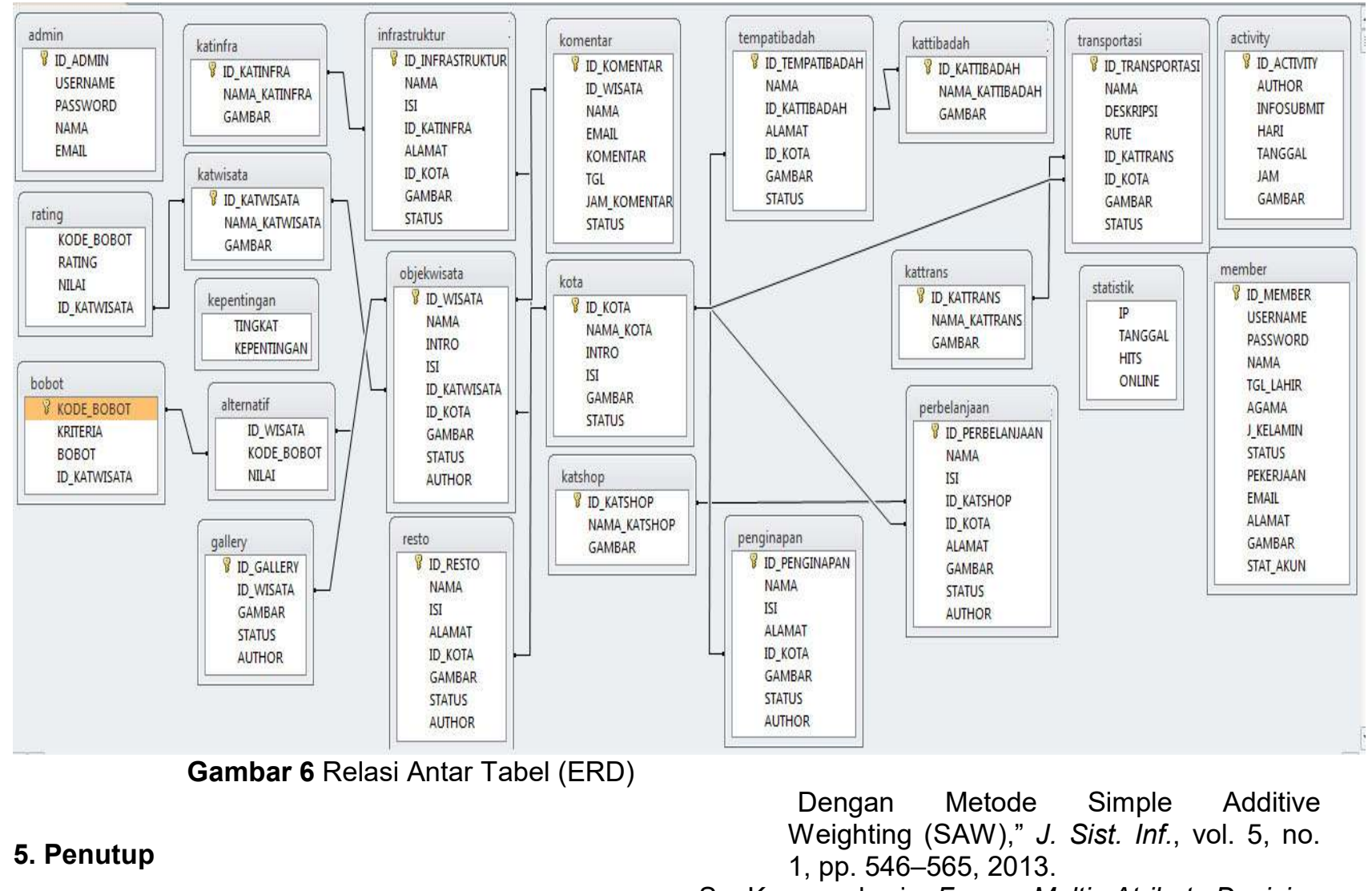

Berdasarkan hasil penelitian dan pembahasan yang telah dilakukan, dapat disimpulkan bahwa S. Kusumadewi, Fuzzy Multi Atribut Decision Making. Yogyakarta: Graha IImu, 2006.

Sistem Informasi Pariwisata yang dirancang dapat menjadi sarana untuk menyimpan informasi mengenai pariwisata Pulau Lombok, membantu wisatawan dalam menentukan objek wisata yang layak dikunjungi berdasarkan tingkat kepentingan pada masing-masing kriteria, dan dapat menjadi media promosi bagi masyarakat yang memiliki usaha di bidang pariwisata.

\section{Pustaka}

A. Nugroho, Analisis dan Perancangan Sistem Informasi. Bandung: Informatika, 2005.

J. E. Turban, Efraim \& Aronson, Decision Support Systems and Intelligent Systems, 6th editio. Upper Saddle River, NJ: Prentice Hall, 2001.

Frieyadie, "Penerapan Metode Simple Additive Weight (Saw) Dalam Sistem Pendukung Keputusan Promosi Kenaikan Jabatan" J. Pilar Nusa Mandiri, vol. XII, no. 37-45, 2016.

A. I. Dwi Citra Hartini, Endang Lestari Ruskan, "Sistem Pendukung Keputusan Pemilihan Hotel Di Kota Palembang 